\title{
TRANSFORMING HIGHER EDUCATION THROUGH ICT AND TRANSPORT INFRASTRUCTURE DEVELOPMENT ${ }^{1}$
}

\begin{abstract}
Which combination of ICT and transport infrastructure development creates a socially richer and supportive environment for commuting university students?
\end{abstract}

The Head of Institutional Planning at the University of the Western Cape (UWC), Mr. Stevens, was working with the 2016 UWC Institutional Operational Plan (IOP) White Paper. He was using this document in his planning. One of the goals of the IOP was the development of the campus and surrounding areas, which required his executive direction. Two intertwined concerns dominated the infrastructure development conversations at UWC: (a) ICT infrastructure development; and (b) student transport improvement.

UWC a university in South Africa, was situated in the City of Cape Town Metropolitan Municipality area, in the Western Cape Province of the Republic of South Africa. The university was situated 24 kilometers from the city centre of Cape Town and was separated from the city's main public transportation routes. Situated in this historically poorer, Apartheid-disadvantaged location and separated from the mainstream residential areas and transport routes of Cape Town, UWC had developed into a commuter-university, with 16,000 of its students commuting daily to UWC from private residences. To this end, the main challenges faced by the UWC students commuting to campus included travelling large distances at high transport costs. Students commuting to UWC traveled along a route with poor Wi-Fi access (see Exhibit 1). This is in contrast to the other historically privileged universities in Cape Town, which were situated in areas that had good access to Wi-Fi.

In addition to being drowned by transport costs, the UWC students were losing a lot of time when traveling between their residence and campus. Therefore, it would have been ideal if the students had access to $\mathrm{Wi}-\mathrm{Fi}$ when travelling to campus. Wi-Fi access would enable the students to use this valuable time much more effectively by engaging in constructive activities related to their studies.

Mr. Stevens stood up and walked towards the Rector's boardroom thinking of which way to steer UWC's infrastructure investment strategy. The decision was more than about ICT and transport infrastructure - it was about developing a nurturing environment that was socially richer and supportive of the students in their academic endeavours at the university.

${ }^{1}$ Copyright (C) 2018, Johan Breytenbach. This case was prepared for the purpose of class discussion. Names and some information have been disguised. This case is published under a Creative Commons BY-NC license and originally appeared as a chapter in Transforming Society Using ICT: Contemporary Discussion Cases from Africa. Permission is granted to copy and distribute this case for non-commercial purposes, in both printed and electronic formats. 


\section{Background}

UWC was established as a university for one of the racial minority groups of South Africa during the Apartheid era. UWC's students mainly came from underprivileged backgrounds. The first students were enrolled in 1960 and with the end of Apartheid in 1994 the student population had grown steadily reaching an estimated 20,000 students at the time of the case. A brief history of UWC, which was accessed from the university's website, is included in Exhibit 2.

\section{ICT \& Transport Infrastructure}

The existing Information and Communication Technology (ICT) and transport infrastructure in the UWC's catchment area had historically been inferior compared to that of the well-off universities in Cape Town. Due to its Apartheid balkanized location that was far from the Cape Town city centre and Bellville, students were forced to commute excessive distances on a daily basis often using costly multiple modes of public transport and in the process passing through unsafe infrastructure-poor areas to reach the UWC main campus. Reaching UWC campus in time for morning lectures was a daily challenge for students from the majority of the UWC catchment area.

Adding to the transport access dilemma, little or no Wi-Fi access was available on any of the major routes or modes of transport leading to UWC. This lack of ICT and dedicated transport infrastructure stood in stark contrast to other historically privileged Cape Town universities that boasted internet-connected university shuttle services, highly developed ICT and public transport infrastructure in their catchment areas, as well as greater on-campus residential capacity.

In order to develop a strategy for the development of the infrastructure of the UWC main campus and influence the City of Cape Town's infrastructural development for improved ICT coverage of the surrounding areas, UWC decided in 2015-2016 to focus on collecting data regarding the transport patterns of its students. The development plans of the university in this respect are contained in Exhibit 3 pertaining to the UWC Institutional Operating Plan.

\section{Problematizing UWC student transportation}

Data related to students commuting was collected using mobile applications. Over one thousand participating UWC students who participated in the survey were asked to identify their daily transport patterns, including details regarding their modes of transport, the duration of their travel, the level of safety of the different parts of each journey, and the availability of free internet access on each portion of their route.

The data of the above mentioned study, which was collected between 2015 and 2016, was correlated with the academic performance data of the participating students. It was envisaged that this investigation would provide guidance on how transport and ICT infrastructure in and around campus should be developed to facilitate optimal academic performance. If, for example, the collected data revealed that students using buses that passed through the Cape Town central business district (CBD), where free onroute Wi-Fi was available, performed academically better compared to other groups, UWC would focus on campaigning for support from the City of Cape Town Metropolitan Municipality to provide Wi-Fi ready dedicated bus lanes on routes used by UWC students. The following is an excerpt from a student about the impact long distance commuting has on their academic performance: 
"I can't complete my group assignments with my study group on campus like the other guys, because I have a two-hour trip back home and it's just not safe to leave after four [16h00]"

It soon became apparent from the initial data analysis that the commonly perceived concerns of transport cost and prolonged travelling time did not actually have as big an impact on academic performance as initially thought (see Exhibit 4 for extracts from the student data analysis).

The data relating to student transport and access to Wi-Fi was taken into consideration during the 2015 and 2016 public hearings, and results emanating from these hearings were incorporated into the updated draft of the Institutional Operation Plan (UWC IOP White Paper, 2016).

The first model that was considered during the hearings was related to institutional subsidy of student transport by UWC, and it soon became apparent that such a model was in the long term not sustainable and therefore not feasible. Given the non-feasibility of this model, the following options were considered: (i) UWC investing in an institutionally owned transport system in the form of UWC shuttles; (ii) increasing UWC's on-campus residential capacity; or (iii) promoting property and infrastructure development around the campus.

\section{Hearings and Challenges}

In several of the hearings, a focus on the core concern of decreasing student-commuting duration and the costs thereof was lost due to the aggressive nature of the 2015-2016 fee-related student protests that were prevailing in South Africa during that period (Naicker, 2016). These protests were called the \#FeesMustFall protests. The resources that were earmarked for this project were therefore simply taken away and directed towards student fees. The student fees protests had forced a moratorium to be placed on fee increases, thus putting pressure on budgeting at the university. Thus, the implementation of the project to address issues relating to long distance commuting and the associated costs as well as ICT connectivity along student bus routes was put on hold and only revived once the student fee protests had subsided. In this regard, possible strategic options for (a) ICT infrastructure development and (b) student transport development were evaluated by the UWC executive management in an environment where UWC had to grapple with future increases in student numbers, and a steep increase in demand on existing infrastructure. One challenge that frequently featured prominently in these discussions was UWC's low on-campus residential holding capacity.

Below is a summary of the points in the debates by management during 2016 and 2017 on the issue of student commuting and internet connectivity along commuting routes:

(1) The \#FeesMustFall protests by the students sensitized many stakeholders on the cost of fees, and other costs related to education in South Africa;

(2) There was the possibility of having even more commuting students in future, with lower government subsidies; 
(3) There existed a historically low level of ICT and transport infrastructure development along prominent UWC commuting routes;

(4) And there existed a historically small on-campus residential holding capacity.

\section{Struggling with on-campus holding capacity}

UWC holding capacity was not keeping pace with the growing enrolment numbers. In 2015, only 23\% of UWC students were accommodated in residences owned or leased by the University, and this number decreased by one percentage point in 2016. UWC's holding capacity in 2016 was 3302 students - a fraction of the total demand for student accommodation in the university.

\section{Existing solutions}

Possible solutions for student accommodation were divided into three categories based on geographic focus area: (1) on campus development; (2) surrounding areas development; and (3) development further afield along the distant bus routes.

\section{On campus}

Although building to increase residential capacity on campus remained an option, space was extremely limited. On-campus ICT access was reliable and on-campus living provided students with access to support services, academic and otherwise. However, the limited space and resources available on campus forced the university to look beyond campus borders towards the surrounding suburbs of Bellville.

\section{Surrounding areas}

At the executive level, a strategic agreement was reached on the development of a "vibrant sub-region with excellent public transportation and ICT infrastructure" around the campus. To illustrate this point, the following statement was extracted from the IOP White Paper (2016):

"UWC has spent significant resources to influence the development of the environment around the University and to secure improvement in transport facilities to mitigate some of the disadvantages of its location. It has had real but limited success...”

In pursuance of this goal, the university acquired two buildings in 2017, both reasonably close to campus and on-route between the UWC main campus and the Bellville town center.

\section{Development along distant bus routes}

As explained by Bulman, Greenwood \& Kingma (2014), the City of Cape Town embarked on developing an integrated rapid transport (IRT) system in 2013. Since 2014, a commitment from the City had resulted in significant improvements in public transport along main commuting routes into the CBD. These improvements included a special bus lane for the exclusive use of the MyCiti bus service. "MyCiti” was the name of the rapid bus transport service of the City of Cape Town, which came with free Wi-Fi along the MyCiti routes. The UWC campus was however not included in any of these developments, because it was not situated in one of the locations that were prioritized for inclusion into the MyCiti development plans by the City of Cape Town. Therefore, the university students did not benefit from these development plans. 
There was a small metro railway station next to the UWC main campus. Coetzee (2013) described efforts to improve the poor and unreliable public train service in Cape Town in an initiative called GoMetro.

According to Jennings (2015), the possibility of constructing public cycling lanes received some media attention in 2014, but such a solution would again have relied heavily on commuting residents staying close to major bus routes.

As noted in the updated UWC IOP White Paper (2016), UWC considered several off-campus transport alternatives, including the costly option of financing the university's own shuttle service. These solutions, if pursued, would have required UWC to work hand-in-hand with the City of Cape Town planners, lobbying for developments of the bus routes used by UWC student and to provide free Wi-Fi on these routes.

\section{Possible investment strategies}

Investment alternatives were on a continuum, ranging from fully subsidized student transport system to development of on-campus student residences. The latter would eliminate the exorbitant costs associated with daily to-and-from campus commuting.

Several other options and combinations of these options that were considered included UWC management influencing local government's development of ICT infrastructure and transport infrastructure in the UWC surrounding areas, or procuring and investing in UWC-owned ICT infrastructure along distant bus routes, as well as procurement of UWC-owned transport. These university owned vehicles would be equipped with internet access for student commuters.

\section{The Decision}

Which way would UWC's management steer investment strategy? Goal 7 of the IOP was more than just about ICT and transport infrastructure - it was about developing a nurturing environment that was socially rich, and academically supportive to the needs of the UWC students.

Mr. Stevens walked towards the board room thinking about the relationships between students who performed better academically and students that had access to on-campus support and ICT services.

\section{References}

CHEC Report on Graduate Development (2013). Pathways from university to work. Retrieved September 2016 online:

http://www.chec.ac.za/files/CHEC\%20Graduate\%20Survey\%20FULL\%20REPORT\%20WEB.p $\underline{\mathrm{df}}$

Bulman, A., Greenwood, G., and Kingma, R. (2014). MyCiti bus rapid transit it is not just about the bus. In: 33rd Annual Southern African Transport Conference, 7-10 July 2014, CSIR International Convention Centre, Pretoria, South Africa. Retrieved July 2018 online: 
https://repository.up.ac.za/bitstream/handle/2263/45541/Bulman_Myciti_2014.pdf?sequence=1\& isAllowed $=\mathrm{y}$

Coetzee, J. (2013). The Emerging Importance of a Mobility Strategy for South African Cities with GoMetro as a Case-Study. Procedia - Social and Behavioral Sciences, 96, pp. 2916-292 6.

Jennings, G. (2015). Finding our balance: considering the opportunities for public bicycle systems in Cape Town, South Africa. Research in Transportation Business \& Management, 15, pp. 6-14.

IOP (2016). University of the Western Cape Institutional Operating Plan [White Paper]. Retrieved September 2016 online: https://ikamva.uwc.ac.za/content/whitepaper.pdf

Naicker, C. (2016). From Marikana to \#feesmustfall: The Praxis of popular politics in South Africa. Urbanisation, 1(1), pp. 53-61. 


\section{Bibliography}

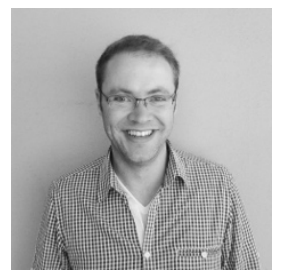

Dr. Johan Breytenbach (PhD) is a researcher in the Information Systems Department at the University of the Western Cape, Cape Town, South Africa. His principal research areas are system design, the impact of platform systems, distributed ledger systems (blockchains) and mobile technologies on business models, and preparing traditional businesses for the digital economy. 


\section{Exhibit 1: Wi-Fi access map in and around the UWC campus}

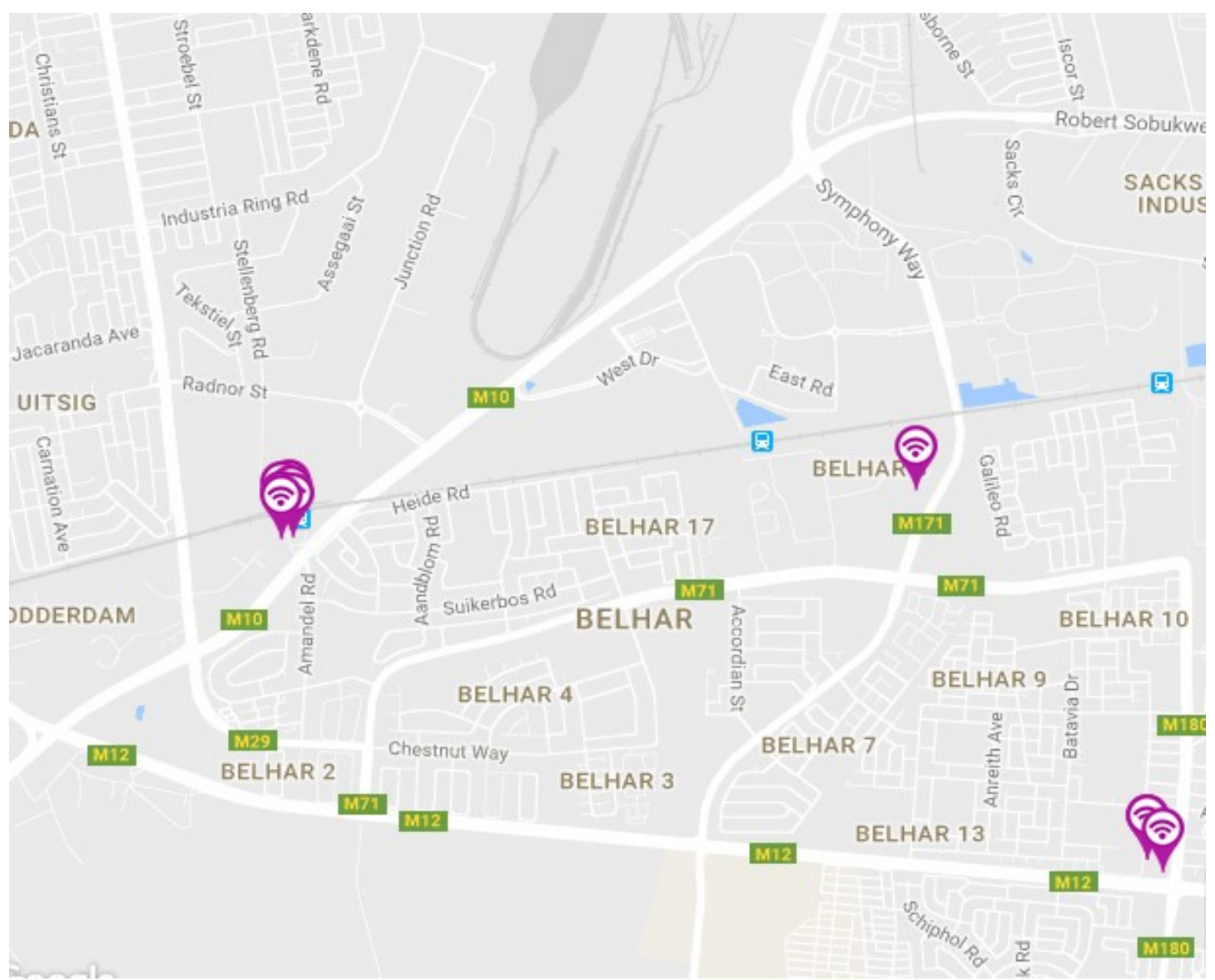

Figure 6: Severe lack of Wi-Fi hotspots near campus

- $\quad$ Students have access to Wi-Fi on campus

- Commuting students have virtually no access to Wi-Fi while travelling, or while stopping over between different modes of transport 
MUMA CASE REVIEW

\section{Exhibit 2: History of the University of the Western Cape}

\section{UWC History}

The University of the Western Cape has a history of creative struggle against oppression, discrimination and disadvantage. Among academic institutions it has been in the vanguard of South Africa's historic change, playing a distinctive academic role in helping to build an equitable and dynamic nation. UWC's key concerns with access, equity and quality in higher education arise from extensive practical engagement in helping the historically marginalised participate fully in the life of the nation.

\section{Early Days}

In 1959, Parliament adopted legislation establishing the University College of the Western Cape as a constituent college of the University of South Africa for people classified as "Coloured". The first group of 166 students enrolled in 1960. What they were offered was limited training for lower to middle level positions in schools, the civil service and other institutions designed to serve a separated Coloured community. In 1970 the institution gained university status and was able to award its own degrees and diplomas.

\section{A Freer Climate}

Protest action by students and black academic staff led to the appointment, in 1975, of the first black Rector. The new, freer climate under the leadership of Professor Richard E (Dick) van der Ross was hospitable to intellectual debate and internationally respected scholarship.

In its mission statement of 1982, UWC Objectives, the university formally rejected the apartheid ideology on which it was established, adopting a declaration of non-racialism and "a firm commitment to the development of the Third World communities in South Africa." In 1983, through the University of the Western Cape Act of 1983, the university finally gained its autonomy on the same terms as the established "white" institutions.

\section{Towards Democracy}

The term of Professor Jakes Gerwel, who took office as Rector in 1987, saw an unambiguous alignment with the mass democratic movement and a new edge to the academic project. Under the banner of "an intellectual home of the left", space was created for curriculum renewal and for innovative research and outreach projects. Important social and policy issues, which had been swept under the carpet by the government of the day, thus received attention.

The university also formalised its "open" admissions policy, providing access to a growing number of African students, and paving the way for rapid growth. Despite severe constraints, students from the 
disadvantaged communities graduated in increasing numbers, equipped to make a professional contribution to the new South Africa. President Nelson Mandela lauded UWC for having transformed itself "from an apartheid ethnic institution to a proud national asset."

\section{New Order}

The 1990's were characterised on the one hand by a sense of rich achievement. UWC was able to play an important role in the emergence of the new democratic order. It provided opportunities for many people to prepare for a wide spectrum of higher-level careers, and played a leading part in policy research and formulation.

UWC takes pride in the fact that so many of its senior academics and alumni found themselves in public office at all levels, a number in the national cabinet.

On the other hand the decade was marked by a strong orientation to the future. There was increased concentration on teaching and learning excellence. UWC's research productivity now places it in the upper group of universities and technikons in the country. A thorough- going review of structures and academic programmes was also begun in the 1990s.

This has led to decisions on consolidation of efforts, to a more interdisciplinary thrust, and to the development of programmes which offer better access to the job market and show a more direct responsiveness to issues of national importance. In the words of Professor Cecil Abrahams, ViceChancellor from 1995, UW C is committed to being "a Place of Quality, a Place to Grow."

\section{Vision of the Future}

Towards the end of 2001 former UWC rector Professor Brian O'Connell assumed the ViceChancellorship amidst a plethora of processes to restructure the higher education system in South Africa. In 2002 the Minister of National Education mapped the future higher education landscape. One of the outcomes of the restructuring process was that UWC would retain its status as an autonomous institution.

Under the visionary leadership of its new Rector, the University is now, more than ever, challenged to demonstrate that it is capable of competing with the best and of playing a prominent role in the intellectual, social and economic life of the nation.

Source: UWC website (https://www.uwc.ac.za/Pages/History.aspx) 


\section{Exhibit 3: Extract from UWC IOP White Paper - September 2016}

\section{GOAL AREA 7: DEVELOPMENT OF THE CAMPUS AND SURROUNDING}

\section{To develop the campus and strategically influence the development of surrounding areas, and to develop and maintain modern, coherent physical and ICT infrastructure}

Its location and the quality of its buildings, equipment, landscape and surrounding areas have a profound influence on UWC. They affect the way it is able to present itself to the outside world and secure support and partnerships, the extent to which 21st century teaching and learning is enabled on campus, and the access students have to cultural and social amenities likely to enrich their education and promote transformation. These concerns have informed planning over many years, and have had particularly concentrated attention over the past decade.

UWC has spent significant resources to influence the development of the environment around the University and to secure improvement in transport facilities to mitigate some of the disadvantages of its location. It has had real but limited success, and these matters will continue to receive planning attention in the period of this IOP. The University has had far more success in improving the landscape, facilities and equipment on its campuses, responding to the changing nature of the academy, and to the steady increase in student numbers. The five years covered in this IOP will see the continuation of an ambitious building plan, the refurbishment and renewal of old buildings on and off the main campus, and the decanting of spaces to be developed for growth, consolidation and ambitious new developments. As an index of the scale of expected change, at least five major capita l projects will be completed by 2019. The outcome will be an expanded campus footprint that is urban in scale and density, with important connections to the fabric of surrounding communities.

Research-intensive universities are generally acknowledged in all major regional planning in the modern world as key catalysts for economic and social transformation. On its campuses there is broad recognition that UWC's long-term best interests lie in suitable development around it: an economically vibrant subregion with excellent public transportation, strong communities, and a range of accessible social and cultural amenities. The primary concern is a connected university with a strong identity and a dignified sense of place, projecting a sense of safety and security.

A number of internal and external imperatives that have been factored into the IOP drive the need for change and will require ongoing strategies to partner with and lobby external agencies to achieve that change. These include:

- the pressing need to influence the development of the broad area around the University so that (a) the City capitalises on the presence of three universities within two kilometres, (b)the universities are reconnected with the mainstream life of the city, and (c) an innovation-friendly precinct brings the universities together in building the regional economy

- a mandate to enrol more undergraduate and postgraduate students 
- growing competition to attract and retain excellent students, teaching staff and researchers

- $\quad$ pressure to be responsive to the changing know ledge economy and the dynamic relationships with business which that calls for in the pursuit of innovation

- advances in technology across a broad front, with major implications for research and teaching.

Taken holistically, these resolve themselves into five challenges the University must address.

- The built environment surrounding the main campus is perceived as uninviting, hostile and sterile reducing the University's impact and cutting its students off from the mainstream life of the city. Aggravating this exclusory effect is that public transport initiatives to improve mobility have largely passed the campus by. This ongoing isolation is a glaring challenge to urban planning. Failure to change the nature of the surroundings, achieve appropriate land use and corridor development conducive to the academic and innovation project will have long-term adverse consequences, not only for UWC, but also for the region's ability to revitalize the surrounding residential areas. UWC is strategically located to be a powerful partner in transforming the whole area into a mode l post-apartheid space and reconnecting it to the mainstream life of the city, but it cannot achieve this alone. As a powerful signal of its vision and commitment, it has acquired a multi-storey Medical Centre in the Bellville CBD. This will help influence the regeneration of a decaying business area and will promote UWC as an anchor institution of note in the sub-region.

- The second challenge concerns growth and the main campus's long -term holding capacity. There is increased land use pressure for academic and professional activities and their support, student residential accommodation, sports facilities, road infrastructure and parking, and places of arrival. To optimise the campus' potential holding capacity and to retain its park-like character requires the University to commit to a future urban collegiate density of $1 \mathrm{~m}^{2}$ of building on $1 \mathrm{~m}^{2}$ of land. The University unquestionably needs more space and will continue actively to explore the acquisition of additional land south of the campus and along the connecting corridor between the campus and its satellite sites in Bellville. UWC lacks the resources to initiate student housing developments on the required scale and will engage a number of $\mathrm{r}$ ole -players to make significantly more accommodation available, developed to the University's specifications. Good residential accommodation and social and cultural facilities have a significant impact on the university’s learning environment, its culture and students’ success.

- A third challenge pertains to the main campus's accessibility, inadequate public transport, increased traffic congestion and perceived public safety and security concerns. There are many positive views about the scale of developments and open spaces on campus, and about the general quality of landscaping and the nature reserve. However, these are qualified by a strong sense that the campus is an island. The sense of isolation is emphasised by the area's being poorly served by public transport systems and the fact that many of the facilities effectively become inaccessible after hours and weekends for those who do not have access to private transport.

- The fourth challenge relates to the rapidly changing and expanding function of information technology. Information technology is a vital component of university life. When IT initiatives are aligned with the university's strategic goa ls, their impact can be phenomena l. As we move deeper into the 21st century, it is important to appreciate the role of Information Technology in 
connecting the campus instantly with the world, enabling high end research, dramatically expanding the range of the classroom, enhancing the student experience, fostering efficient administration, and facilitating strong communication among internal and external communities. It is a key enabler of any modern university's core academic, research and operational goals and, as it is increasingly available in various forms, its use becomes second nature. Today's tech-savvy students and staff prefer an interactive and engaging experience and expect flexible and secure IT tools, systems and spaces to be available to them inside and outs ide the classroom. Universities face a large and growing challenge to use technology creatively to meet learning, research, administrative and support goa ls across a broad front. UWC has embraced the challenge. It is increasingly a "smart" university, and the opportunities that represents are more and more exciting.

- The fifth challenge relates to keeping the main and satellite campuses connected. UWC's main campus is in Bellville South. Its oldest satellite campus is the Dentistry Faculty building in Mitchell's Plain. It has a further Dentistry satellite campus in Parow, in c lose proximity to Tygerberg Hospital. And its most recent in the Bellville CBD. Students and staff in all these campuses must feel connected. Better physical connectivity through suitable development of the region and improved public transport would make a major difference. And high- level real time classroom connectivity can overcome many obstacles. 


\section{Exhibit 4: Extracts from UWC student transport study}

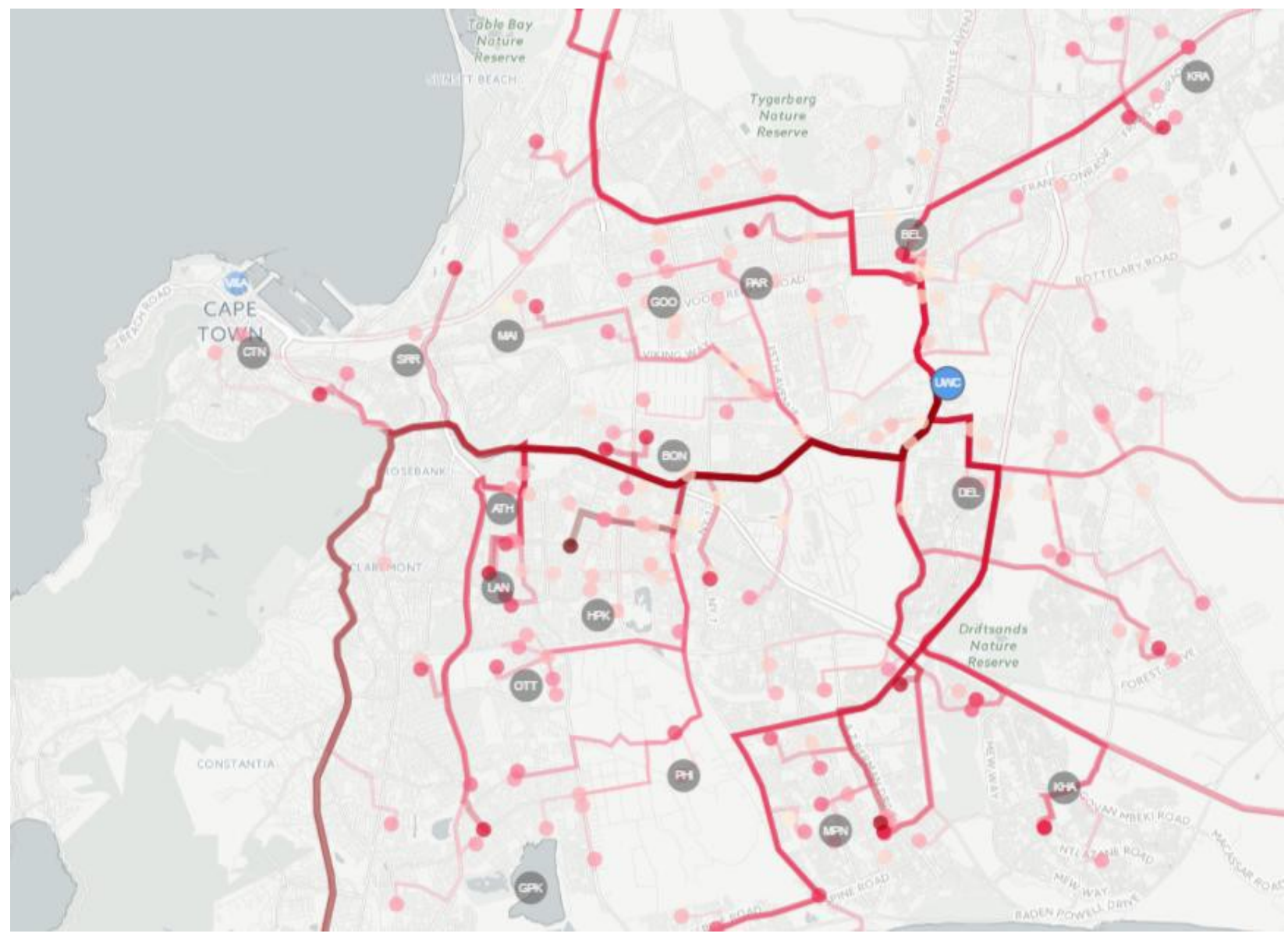

Map view A: Commuting routes to UWC main campus (majority via N2 and Robert Sobukwe road) 


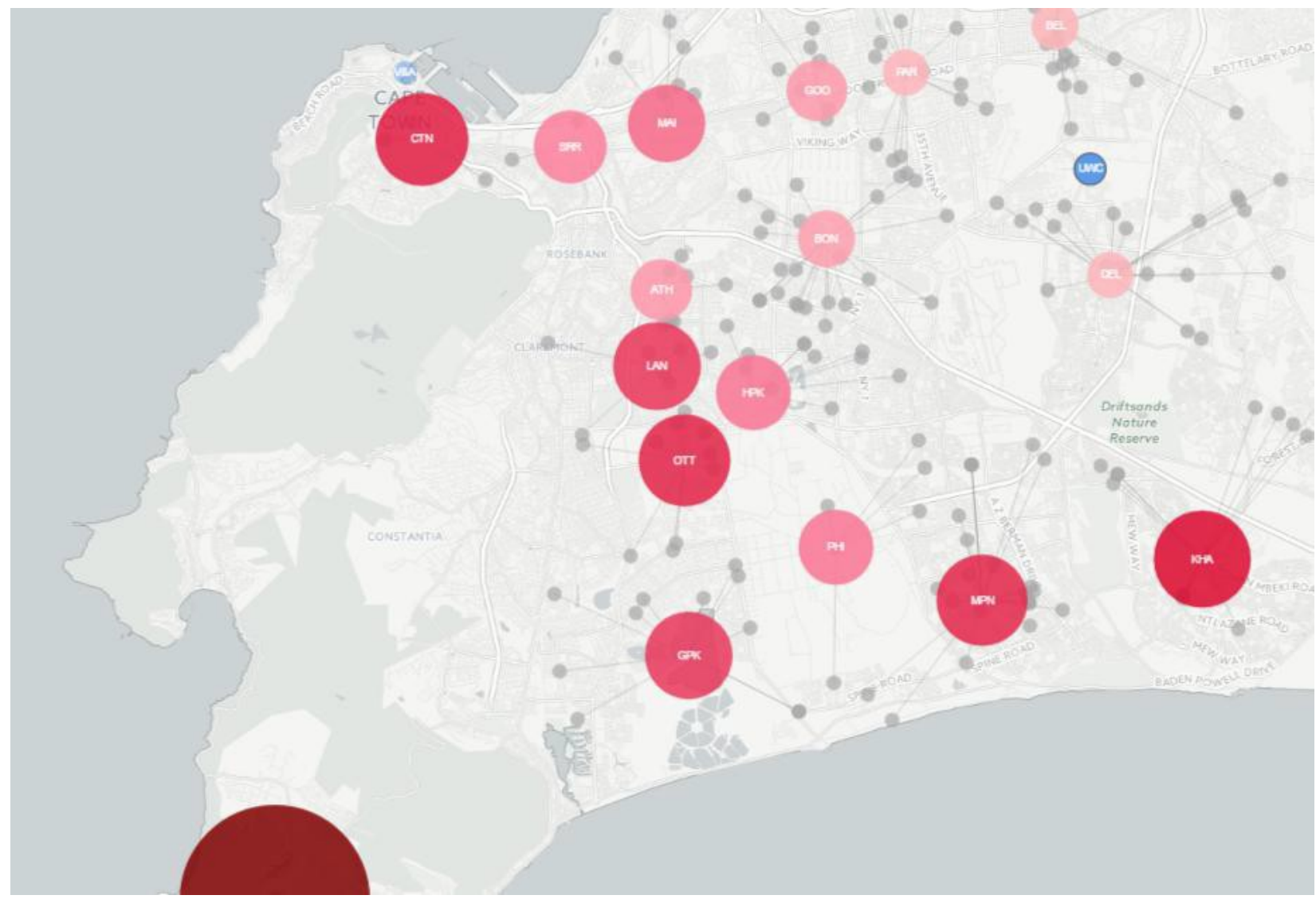

Map view B: Commuting times UWC main campus (1 $\mathrm{cm}$ circle diameter = 1 hour $)$

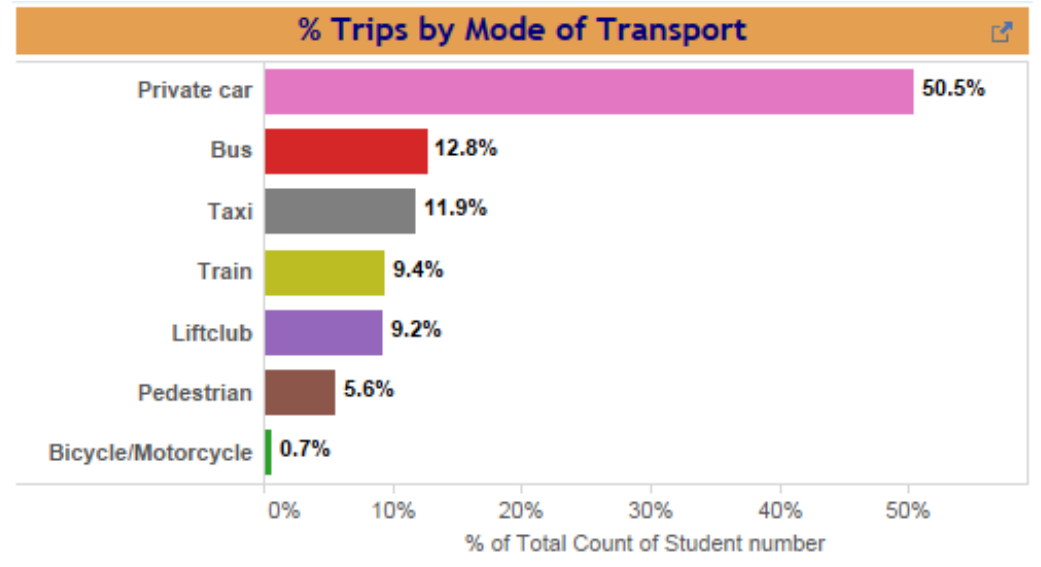

Figure 1: Percentage of students per mode of transport 
- Majority of students use private cars for daily commute to UWC

- No clear target for transport subsidy strategy

- UWC campus is not close enough to major public transport routes

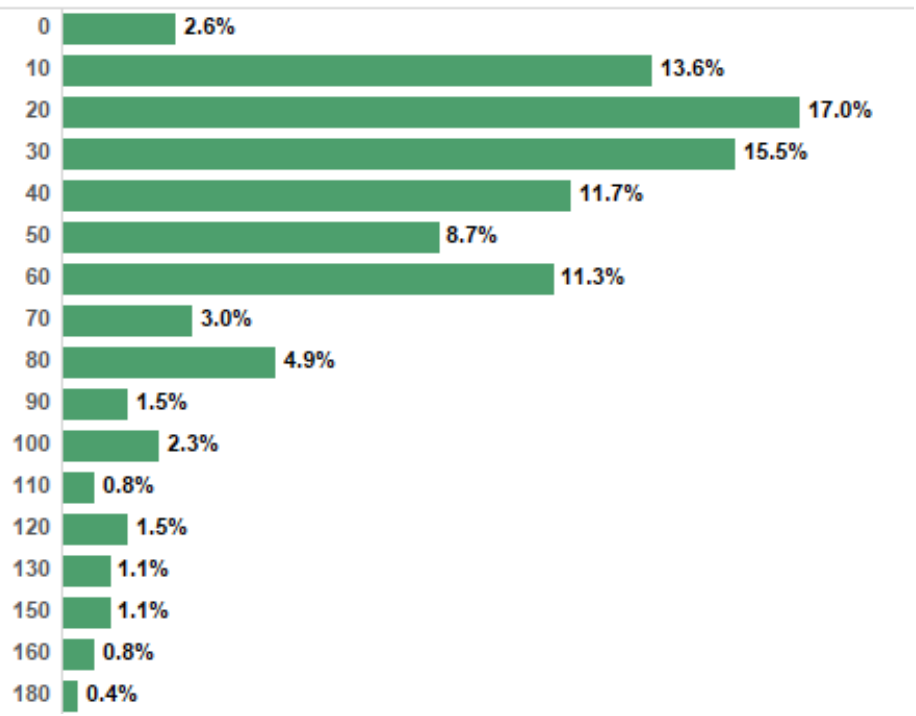

Figure 2: Percentage of students per number of minutes travelled

- Majority of students travel less than 1 hour (including stop-over times) to commute to UWC

- There are several students traveling longer than 2 hours to reach UWC

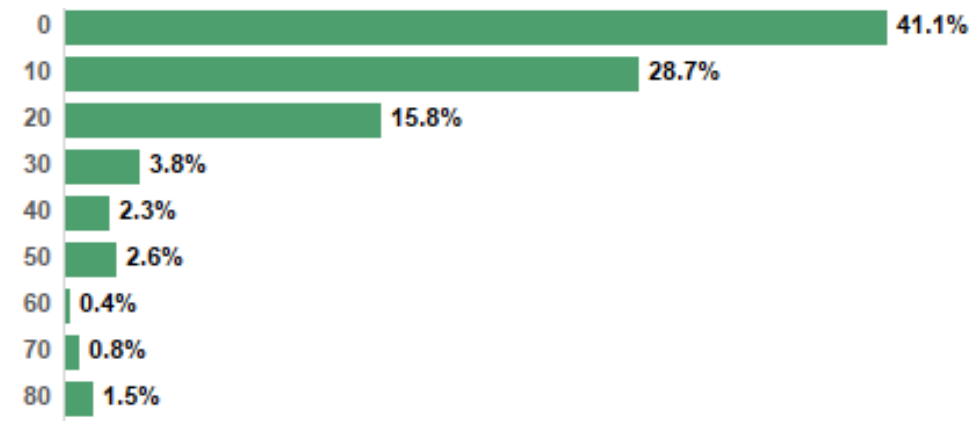

Figure 3: Percentage of students per cost bracket (ZAR)

- Largest percentage of students pay less than R10 to reach UWC from home (one way) - cost of using private vehicle

- A significant portion of students pay between R10 and R30 (one way) to reach UWC from home 
The link between commuting habits and academic performance

\begin{tabular}{|c|c|}
\hline Suburbs & 5 \\
\hline Bellville & $52 \%$ \\
\hline Lavistown & $52 \%$ \\
\hline Cape Town & $51 \%$ \\
\hline Mitchells Plain & $52 \%$ \\
\hline Matroosfontein & $52 \%$ \\
\hline Athlone & $53 \%$ \\
\hline Eerste River & $52 \%$ \\
\hline Parow & $52 \%$ \\
\hline Gatesville & $51 \%$ \\
\hline Kuils River & $52 \%$ \\
\hline Ravensmead & $52 \%$ \\
\hline Goodwood & $51 \%$ \\
\hline Delft & $52 \%$ \\
\hline Ottery & $51 \%$ \\
\hline Guguletu & $52 \%$ \\
\hline Brackenfell & $50 \%$ \\
\hline Kraaifontein & $53 \%$ \\
\hline Lansdowne & $52 \%$ \\
\hline Milnerton & $50 \%$ \\
\hline Rondebosch & $49 \%$ \\
\hline Belhar & $50 \%$ \\
\hline Durbanville & $53 \%$ \\
\hline
\end{tabular}

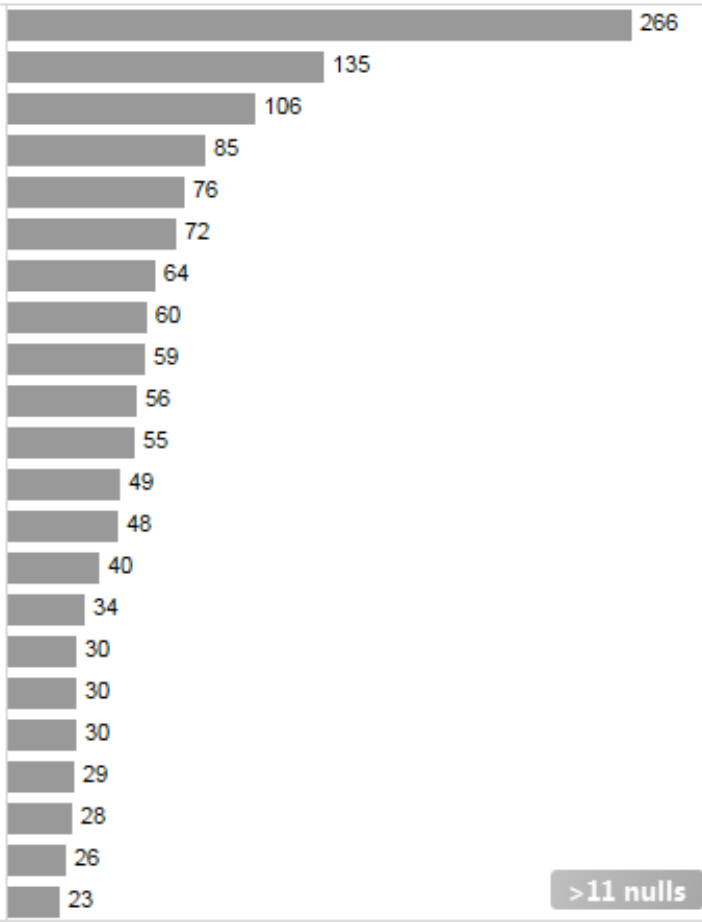

Figure 4: Average marks per suburb (left) - with number of students per suburb (right)

No correlation or clear achievers - no relationship between where student lives and academic performance

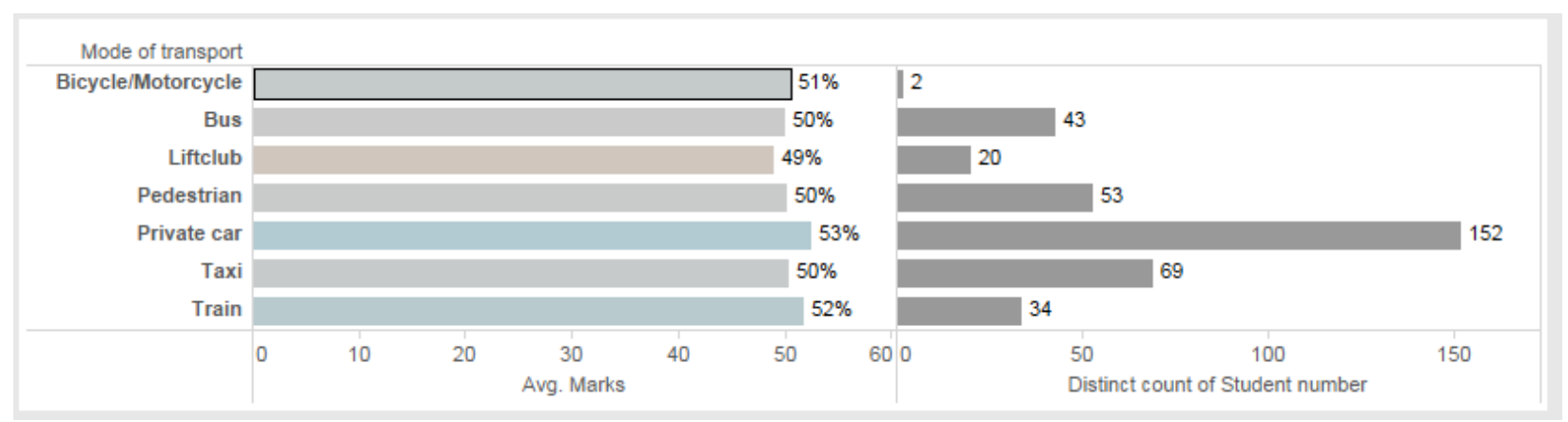

Figure 5: Average marks per mode of transport (left) - with number of students per mode (right)

No correlation or clear achievers - no relationship between how student travels and academic performance 